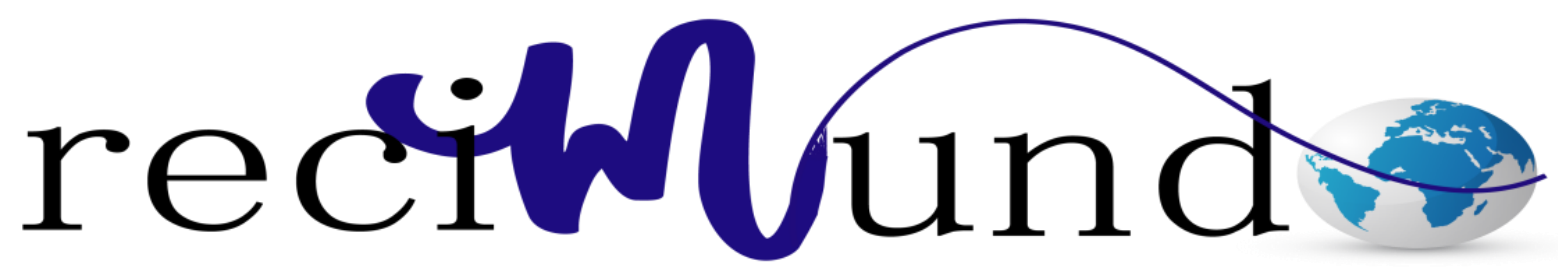

Revista Científica Mundo de la Investigación y el Conocimiento

Francisco Bolívar Zurita Rosero ${ }^{\text {a }}$; María Gabriela Zurita Montaño ${ }^{\text {; }}$; Carlos Efren Farhat Zamora ${ }^{c}$; Juana Alexandra Narvaez Sarasti ${ }^{\mathrm{d}}$

La Hepatitis como enfermedad de transmisión sexual (ETS)

Hepatitis as a sexually transmitted disease

Revista Científica Mundo de la Investigación y el Conocimiento. Vol. 2 núm.3, julio, ISSN: 2588-073X, 2018, pp. 227-241

DOI: 10.26820/recimundo/2.(3).julio.2018.227-241

Editorial Saberes del Conocimiento

Recibido: 05/04/2018

Aceptado: 15/02/2018

Publicado: 30/07/2018

Correspondencia: fbzurita@uees.edu.ec
a. Universidad Espíritu Santo; fbzurita@uees.edu.ec
b. Universidad Espíritu Santo; mariazurita@uees.edu.ec
c. Universidad Espíritu Santo; cfarhat@uees.edu.ec
d. Universidad Espíritu Santo; anarvae@uees.edu.ec 


\section{La Hepatitis como enfermedad de transmisión sexual (ETS)}

Vol. 2, núm. 3., (2018)

Francisco Bolivar Zurita Rosero; María Gabriela Zurita Montaño; Carlos Efren Farhat Zamora; Juana Alexandra Narvaez Sarasti

\section{RESUMEN}

Este trabajo es una recopilación de información y textos que sintetizan la transmisión de la enfermedad o virus de la hepatitis por medio de relaciones sexuales. El estudio de los diferentes tipos de hepatitis y las posibles causas de contagio y tratamiento. A través del conocimiento de enfermedades de transmisión sexuales y de una investigación a fondo de los tipos de virus de hepatitis en donde se observó que la hepatitis B es la que principalmente se transmite por medio de relaciones sexuales, esto debido a que el virus se aloja en las secreciones liquidas de las personas como el semen o fluidos vaginales y la sangre por lo que su forma de contagio es comparada con la de VIH. El trabajo hace mención a los diferentes síntomas de la hepatitis determinando el más importante y visorio la presencia de ictericia donde la persona toma color amarillo en la piel, ojos y mucosas producto de la presencia de bilirrubina en la sangre debido a la inflamación del hígado y a que no está funcionando adecuadamente lo que no hace posible que este órgano metabolice esta sustancia dejándola en la sangre ocasionando también heces claras (debido a la ausencia de la bilirrubina en las heces) y orina oscura debido a la presencia de la bilirrubina en la sangre. En el trabajo también se observa que el tipo el virus de hepatitis B es considerado un problema a nivel mundial y que los casos crónicos representan cifras de casi 400 millones de portadores.

Palabras Claves: Hepatitis, Enfermedad, Hígado, Inflamación, Virus. 


\title{
La Hepatitis como enfermedad de transmisión sexual (ETS)
}

Vol. 2, núm. 3., (2018)

Francisco Bolivar Zurita Rosero; María Gabriela Zurita Montaño; Carlos Efren Farhat Zamora;

Juana Alexandra Narvaez Sarasti

\begin{abstract}
This work is a compilation of information and texts that synthesize the transmission of hepatitis disease or virus through sexual intercourse. The study of the different types of hepatitis and the possible causes of infection and treatment. Through the knowledge of the diseases of transmission and infection by hepatitis A virus in which hepatitis B is a virus that is inherited because of hepatitis B is the liquid secretions of people like semen from fluids vaginal and blood so that its form of infection is compared with that of HIV. The work has mentioned the different symptoms of hepatitis determining the most important and visor the presence of jaundice in the person takes yellow color in the skin, eyes and mucous product of the presence of bilirubin in the blood that is not working properly, which is It is possible that this organ metabolizes this substance leaving it in the blood causing also clear stools and due to the presence of bilirubin in the blood. At work, it was also observed that the type of hepatitis B virus was a worldwide problem and that chronic cases represented figures of almost 400 million carriers.
\end{abstract}

Keywords: Hepatitis, Disease, Liver, Inflammation, Virus. 


\section{La Hepatitis como enfermedad de transmisión sexual (ETS)}

Vol. 2, núm. 3., (2018)

Francisco Bolivar Zurita Rosero; María Gabriela Zurita Montaño; Carlos Efren Farhat Zamora; Juana Alexandra Narvaez Sarasti

\section{Introducción.}

Las enfermedades de transmisión sexual son infecciones originadas a través de las relaciones sexuales. Esto se debe a un sinfín de virus bacterias y parásitos que pueden existir en los genitales de una persona y que a través del acto sexual se transmiten de una persona a otra.

En los órganos sexuales habitan una gran cantidad de bacterias que son quienes mantienen en el caso de la vagina el ph regulado. "Normalmente el lactobacilo es el que se encarga de mantener en equilibrio el $\mathrm{Ph}$ de la que siempre debe estar entre 3,5 y 4,5 por lo que cualquier alteración en el mismo puede suponer molestias más o menos graves en esta zona así como también la aparición de de infecciones suaves o graves" (Saludsexualyvidasana.com, 2014).

Sin embargo el aparato reproductor masculino también es vulnerable a la aparición de infecciones, "un gran número de bacterias puede colonizar el tracto reproductivo masculino y desencadenar procesos infecciosos con múltiples consecuencias. Este tipo de infecciones se caracterizan por ser comunes pero generalmente autolimitadas y en la gran mayoría de los casos asintomáticos, lo que le da el carácter de infección crónica acompañada en algunas ocasiones de inflamación persistente” (Jenniffer Puerta-Suárez, 2014).

Entre las enfermedades de transmisión sexuales más comunes son la sífilis, la gonorrea, la clamidia, el Virus del Papiloma Humano (VPH), las hepatitis B y C, el VIH estas enfermedades se presentan en hombres y mujeres de cualquier edad y orientación sexual. 


\section{La Hepatitis como enfermedad de transmisión sexual (ETS)}

Vol. 2, núm. 3., (2018)

Francisco Bolivar Zurita Rosero; María Gabriela Zurita Montaño; Carlos Efren Farhat Zamora; Juana Alexandra Narvaez Sarasti

La hepatitis es una inflamación del hígado. La afección puede remitir espontáneamente o evolucionar hacia una fibrosis (cicatrización), una cirrosis o un cáncer de hígado. Los virus de la hepatitis son la causa más frecuente de las hepatitis, que también pueden deberse a otras infecciones, sustancias tóxicas (por ejemplo, el alcohol o determinadas drogas) o enfermedades autoinmunitarias. (Salud, 2014).

Según (Salud A. , 2017), existen diferentes tipos de hepatitis entre estos estan la hepatitis A, B, C, D y E, todos estan relacionados con enfermedades hepáticas pero se diferencian entre si por su modo de transmision y sus consecuencias.

La hepatitis A y la E son causadas generalmente por la ingestión de agua o alimentos contaminados. Las hepatitis B, C y D se producen por el contacto con humores corporales infectados. Son formas comunes de transmisión de estos últimos la transfusión de sangre o productos sanguíneos contaminados, los procedimientos médicos invasores en que se usa equipo contaminado y, en el caso de la hepatitis B, la transmisión de la madre a la criatura en el parto o de un miembro de la familia al niño, y también el contacto sexual. (Salud, 2014).

El virus de hepatitis A (VHA), sin embargo también puede transmitirse en algunos casos por transmisión sexual, este virus se ubica en las heces de las personas por lo que se hace propenso que por medio de relaciones sexuales de tipo anal se transmita el virus de persona a persona, mientras que el virus de hepatitis $\mathrm{B}$ (VHB) si está totalmente relacionada con la transmisión sexual, ya que, esta se contagia a través de la exposición de sangre, semen y otros líquidos corporales infecciosos. 


\section{La Hepatitis como enfermedad de transmisión sexual (ETS)}

Vol. 2, núm. 3., (2018)

Francisco Bolivar Zurita Rosero; María Gabriela Zurita Montaño; Carlos Efren Farhat Zamora; Juana Alexandra Narvaez Sarasti

El virus de hepatitis C (VHC) es transmitido por medio de de la manipulación de sangre contaminada bien sea por transfusiones o el uso de instrumentos de medicina infectados con el virus y también por el consumo de drogas inyectables. El virus por hepatitis D (VHD) solo se transmite a personas que han sido contagiadas por VHB es decir por la hepatitis de transmisión sexual, en este caso ocurre una fusión entre ambos virus que ocasiona afecciones sumamente graves y que pueden desencadenar un desenlace peor.

El virus de hepatitis E (VHE) al igual que el VHA se transmite por el consumo de aguas y alimentos contaminados este tipo se relaciona con brotes epidemiológico en países subdesarrollados en donde las personas no tienen muchos acceso a las pruebas y tratamientos necesarios para combatir la enfermedad.

En la mayoría de los tipos de virus de hepatitis existen vacunas que ayudan a contrarrestar la enfermedad evitando brotes por pandemias y previniendo la infección, sin embargo la hepatitis del tipo $\mathrm{C}$ en la única que no tiene vacuna.

En vista de lo realmente preocupante que pueden ser las enfermedades de transmisión sexual y que a pesar de que la hepatitis es una enfermedad de origen hepático, es de suma importancia tener presente que este tipo de enfermedad también puede transmitirse a través de actos sexuales lo que prende una alarma en la población y las parejas de cualquier orientación sexual a mantener un cuidado minucioso y estar alertas de presentar síntomas que tienen que ver con la sospecha de la aparición del virus de hepatitis.

\section{Métodos y materiales.}




\section{La Hepatitis como enfermedad de transmisión sexual (ETS)}

Vol. 2, núm. 3., (2018)

Francisco Bolivar Zurita Rosero; María Gabriela Zurita Montaño; Carlos Efren Farhat Zamora;

Juana Alexandra Narvaez Sarasti

Esta investigación está enfocada en el estudio de la hepatitis vista como una enfermedad de transmisión sexual y en el estudio de los distintos tipos de virus de hepatitis sus formas de contagio, diagnóstico y tratamiento, a través del conocimiento de los síntomas que se relacionen con la aparición del virus de hepatitis en cualquier individuo.

La revisión se ha centrado en textos, documentos y artículos científicos publicados disponibles en la web, considerando que aquella herencia de la globalización nos permite acceder a mayor y mejor información a través de las herramientas tecnológicas. El motor de búsqueda ha sido herramientas académicas de la web que direccionan específicamente a archivos con validez y reconocimiento científico, descartando toda información no confirmada o sin las respectivas referencias bibliográficas

\section{Resultados.}

A pesar de que la hepatitis es una enfermedad que se presenta como una inflamación en el hígado y puede pensarse que sus causas va más hacia la transmisión por ingesta de líquidos contaminados con el virus, estudios han demostrado que esta enfermedad también puede transmitirse por medio de la práctica sexual ya que uno de los tipos de virus se aloja en el semen o en las heces de la persona contagiada.

El virus de la hepatitis B es la que más se asocia a la transmisión sexual, este en sus diversas formas de transmisión es similar al VIH, a través de sangre y fluidos corporales como semen, secreción vaginal y otros por lo que la prevalencia de esta infección es elevada en personas en contacto frecuente con sangre como enfermos sometidos a diálisis, personal hospitalario en contacto frecuente con sangre, usuarios de drogas endovenosas, y en personas 


\section{La Hepatitis como enfermedad de transmisión sexual (ETS)}

Vol. 2, núm. 3., (2018)

Francisco Bolivar Zurita Rosero; María Gabriela Zurita Montaño; Carlos Efren Farhat Zamora; Juana Alexandra Narvaez Sarasti

que tienen múltiples parejas sexuales como homosexuales o meretrices, aunque la eficacia de la transmisión es baja. (MUÑOZ Dany, 2007).

Muchas enfermedades y complicaciones pueden causar hepatitis, por ejemplo, uso de drogas, medicamentos, exceso o uso crónico de alcohol, productos químicos, enfermedades autoinmunes, infecciones por diversos tipos de virus o acumulación de grasa en el hígado. Aunque hay varias causas para la aparición de la hepatitis, sus síntomas son todos semejantes lo que se resumen a un hígado inflamado que no es capaz de trabajar adecuadamente.

A continuación se presentan los síntomas que prenden un alerta por la posible aparición del virus de hepatitis:

La Ictericia: Es el síntoma más característico de la hepatitis, sucede cuando la piel, los ojos y las mucosas de las personas contagiadas toman una coloración amarillenta. Esto sucede por la acumulación de bilirrubina en la sangre, ya que, al estar el hígado enfermo o inflamado no es capaz de metabolizar o eliminar la bilirrubina producto de la destrucción en el bazo de los hematíes o glóbulos rojos donde uno de los elementos que se libera es la bilirrubina que es de color amarillo provocando la acumulación de la sustancia en la sangre y haciéndose notoria en piel ojos y mucosas. 


\section{La Hepatitis como enfermedad de transmisión sexual (ETS)}

Vol. 2, núm. 3., (2018)

Francisco Bolivar Zurita Rosero; María Gabriela Zurita Montaño; Carlos Efren Farhat Zamora; Juana Alexandra Narvaez Sarasti

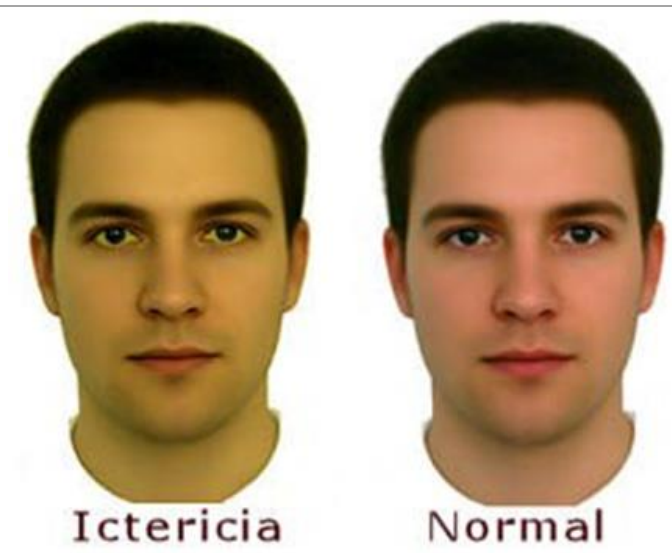

Fuente: (Pinheiro, 2018).

\section{Imagen $N^{o} 1$. Presencia de Ictericia}

Acolia Fecal: Es la presencia de heces claras casi blancas, está relacionado a la NO metabolización o eliminación de la bilirrubina por las heces, ya que, este elemento es el que se encarga de dar coloración a las heces, al no haber presencia de bilirrubina en los intestinos las heces se tornan blancas lo que indica que no hay un adecuado funcionamiento del hígado y por ende existe presencia del virus de hepatitis.

Orina oscura: este es otro síntoma de la presencia de hepatitis ya que se produce debido a la acumulación de la bilirrubina en la sangre. "El papel de los riñones en nuestro organismo es el de filtrar la sangre, eliminando sustancias innecesarias o en exceso. Y es exactamente eso lo que hacen los riñones en los pacientes con ictericia: excretan el exceso de bilirrubina, que por ser un pigmento oscuro, acaba oscureciendo la orina, dejándola con color de Coca-Cola o mate" (Pinheiro, 2018).

Comezón difusa en la piel: La ictericia viene frecuentemente asociada a la comezón, pues la bilirrubina depositada en la piel causa irritación de las terminaciones nerviosas. 


\section{La Hepatitis como enfermedad de transmisión sexual (ETS)}

Vol. 2, núm. 3., (2018)

Francisco Bolivar Zurita Rosero; María Gabriela Zurita Montaño; Carlos Efren Farhat Zamora; Juana Alexandra Narvaez Sarasti

Dolor abdominal: La inflamación de la hepatitis puede causar una hinchazón en el hígado causando un dolor que se refleja a nivel de abdomen. "El dolor de la hepatitis está localizado, característicamente, en el cuadrante superior derecho del abdomen, justo debajo de las costillas, exactamente en la parte donde se encuentra el hígado”. (Pinheiro, 2018).

Malestar: La hepatitis siempre causa un cuadro poco específico de malestar, que puede incluir diversos síntomas, como debilidad, cansancio fácil, pérdida del apetito, dolor muscular, dolor articular, diarrea, rash (manchas rojas en el cuerpo), náuseas y vómitos. (Pinheiro, 2018).

Fiebre: Otra de las manifestaciones de hepatitis es la presencia de fiebre y a pesar de ser fiebre baja, está asociada a otras características poco comunes que se relacionan con los tipos de malestares que se presenta.

Insuficiencia hepática aguda: En algunas ocasiones la presencia de hepatitis puede presentarse como una falla aguda del hígado, esto sucede cuando se trata de una hepatitis fulminante. La inflamación es tan fuerte que el hígado deja de funcionar por completo.

La hepatitis viral constituye uno de los problemas de salud que con mayor frecuencia ataca a la población mundial, notificándose actualmente entre 10000 y 20000 casos. La hepatitis B (HB) es considerada un importante problema de salud pública mundial, por su distribución geográfica, por la vulnerabilidad de este tipo de virus al contagiarse a través de relaciones sexuales debido a su presencia en fluidos como el semen o fluidos vaginales. El número de portadores crónicos es de alrededor de 400 millones y su relación con enfermedades 


\section{La Hepatitis como enfermedad de transmisión sexual (ETS)}

Vol. 2, núm. 3., (2018)

Francisco Bolivar Zurita Rosero; María Gabriela Zurita Montaño; Carlos Efren Farhat Zamora; Juana Alexandra Narvaez Sarasti

hepáticas crónicas y hepatocarcinomas hace parecer un problema en la salud pública mundial causando más de 1 millón de muertes anuales. (Acosta, 2000).

En un estudio realizado por (Oscar Beltrán Galvis, 2005), se tiene la prevalencia de la infección por VHB y los patrones de transmisión varían ampliamente en diferentes regiones, oscilando entre un 8\% en áreas altamente endémicas como África, Asia (excluyendo Japón), la Cuenca del Pacífico y la Cuenca amazónica; a menos del 2\% en los países occidentales EEUU y Europa. En las áreas de alta endemicidad, 70\% a 90\% de la población general tiene evidencia serológica de infección por VHB antigua o reciente. En estas áreas, la infección es transmitida perinatal o tempranamente en la infancia $(<5$ años $)$, mientras, que en áreas de endemicidad intermedia y baja, es probable que la transmisión ocurra tardíamente en la infancia o en edad adulta por vía horizontal (sexual, drogas endovenosas o exposición ocupacional.

Los pacientes con infección crónica por $\mathrm{VHB}$, típicamente son referidos, cuando una serología viral es informada con $\mathrm{HBs} \mathrm{Ag}(+)$. El perfil virológico completo de los pacientes con sospecha de infección crónica por VHB involucra:

1. El estado del HBe Ag y de los anticuerpos contra el HBe Ag ( anti HBe).

2. El estado del Anticuerpo contra el Core ( AntiHBc ).

3. El perfil hepático, especialmente las amino-transferasas.

4. DNA viral del VHB. 


\section{La Hepatitis como enfermedad de transmisión sexual (ETS)}

Vol. 2, núm. 3., (2018)

Francisco Bolivar Zurita Rosero; María Gabriela Zurita Montaño; Carlos Efren Farhat Zamora; Juana Alexandra Narvaez Sarasti

Para determinar la naturaleza y fase de la infección se requieren primero determinar si la infección es aguda o crónica y segundo una vez que la infección aguda ha sido excluida, debe evaluarse el estado del $\mathrm{HBeAg}$, conjuntamente con las aminotransferasas. A continuación se presenta un algoritmo de diagnostico de hepatitis B.

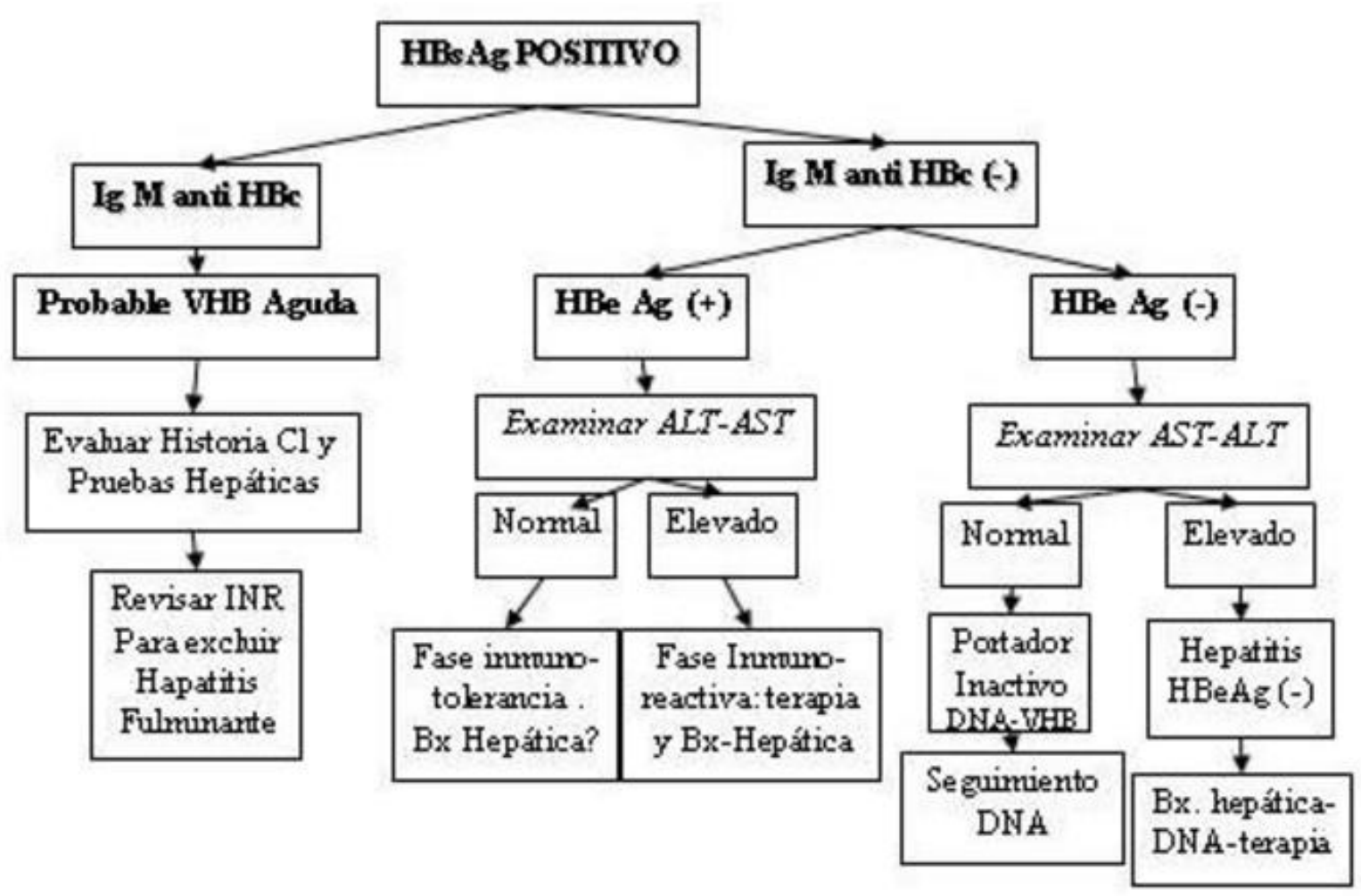

Revista Científica Mundo de la Investigación y el Conocimiento. 2 (3). pp. 227-241 


\section{La Hepatitis como enfermedad de transmisión sexual (ETS)}

Vol. 2, núm. 3., (2018)

Francisco Bolivar Zurita Rosero; María Gabriela Zurita Montaño; Carlos Efren Farhat Zamora;

Juana Alexandra Narvaez Sarasti

\section{Imagen $\mathrm{N}^{o}$ 2. Algoritmo de diagnóstico de hepatitis B crónica}

Fuente: (Oscar Beltrán Galvis, 2005).

La enfermedad es diagnosticada a través de exámenes de sangre en donde se evidencia el aumento de los niveles en sangre de las transaminasas, enzimas que son liberadas a la sangre por la muerte celular producida por la inflamación del hígado. El diagnóstico se completa con otras determinaciones analíticas que, además, ayudarán a encontrar la causa de la hepatitis y a determinar su severidad y su pronóstico. Para el diagnóstico definitivo es necesario en muchos casos realizar una biopsia hepática. (Sangro, 2015).

Los tratamientos aplicados a las enfermedades causadas por el virus de la hepatitis básicamente van a depender del tipo de virus (A, B, C, D, E), por lo general los médicos recomiendan al paciente guardar reposo absoluto, descansar y tomar mucha agua, evitar la ingesta de alcohol y controlar las náuseas, mantener una dieta especial así como también se recomienda vacunarse contra los distintos casos de hepatitis y en el caso del virus B mantener relaciones sexuales con protección para evitar el contagio.

\section{Conclusiones.}

Haciendo un análisis de los resultados presentados en el trabajo se observó que existen diferentes tipos de hepatitis (A, B, C, D y E), que todos presentan los mismos síntomas pero que se diferencian entre sí por la forma de transmisión, en este caso se estudió más a fondo el virus de hepatitis B en donde se determinó que este se aloja en los fluidos corporales como la saliva, sudor y semen y por lo que está determinado que se transmite a través de prácticas sexuales. 


\section{La Hepatitis como enfermedad de transmisión sexual (ETS)}

Vol. 2, núm. 3., (2018)

Francisco Bolivar Zurita Rosero; María Gabriela Zurita Montaño; Carlos Efren Farhat Zamora; Juana Alexandra Narvaez Sarasti

En el desarrollo de la investigación se observó que los principales síntomas que podrían presentar alerta por la aparición del virus de hepatitis es la ictericia o color amarillento en piel mucosas y ojos, también la presencia de heces de color clara producto de la ausencia de la bilirrubina en las heces debidos a la inflamación que presenta el hígado y que no es capaz de funcionar adecuadamente metabolizando esta sustancia de la sangre lo que hace que se acumule y provoque la piel amarilla en las personas, las heces blancas y la orina oscura.

Se determinó que la hepatitis viral representa uno de los problemas más críticos en salud a nivel mundial notificándose casos de 10.000 y 20.000, que el virus de la hepatitis B es uno de los más preocupante reportándose alrededor de 400 millones de portadores crónicos, esto debido a que este tipo de hepatitis es transmitido a través de transmisión sexual lo que lo hace más vulnerable al contagio.

El virus de la hepatitis B puede pasar de ser aguda a crónica si no se mantienen los cuiadado y el tratamiento preventivo necesario para evitarlo y es por la reincidencia del virus en el cuerpo de la persona contagiada, en el trabajo se presentó esto un algoritmo de diagnóstico de hepatitis B crónico.

Lo más recomendado en el caso de presentar hepatitis es guardar reposo absoluto, tomar abundante agua mantener una dieta especial y evitar por 6 meses la ingesta de alcohol para dar mayor recuperación al hígado.

Finalmente se puede concluir que a pesar de que la hepatitis representa una inflamación en el hígado es muy probable que esta pueda ser transmitida por medios de actos sexuales como es el caso de la hepatitis B y en algunos casos la hepatitis A debido que esta última se aloja en las 


\section{La Hepatitis como enfermedad de transmisión sexual (ETS)}

Vol. 2, núm. 3., (2018)

Francisco Bolivar Zurita Rosero; María Gabriela Zurita Montaño; Carlos Efren Farhat Zamora; Juana Alexandra Narvaez Sarasti

heces de las personas contagiadas y se ha comprobado que en algunas prácticas sexuales las personas pueden contraer virus de hepatitis A.

\section{Bibliografía.}

Acosta, C. R. (2000). Actualización sobre hepatitis viral: etiología, patogenia, diagnóstico microbiológico y prevención.

Jenniffer Puerta-Suárez, M. G.-M. (2014). Infecciones bacterianas del tracto reproductivo masculino y su papel en la fertilidad.

MUÑOZ Dany, T. L. (2007). Prácticas sexuales de riesgo y seroprevalencia de infección por VIH-1. HTLV-1, sífilis y hepatitis B en varones drogadictos no endovenosos de Lima.

Oscar Beltrán Galvis, M. R. (2005). Hepatitis B: Diagnóstico y manejo.

Pinheiro, D. P. (07 de Marzo de 2018). 8 SÍNTOMAS DE LA HEPATITIS. Obtenido de https://www.mdsaude.com/es/2015/10/sintomas-de-la-hepatitis.html

Salud, A. (2017). Afemefa.com. Obtenido de https://afemefa.com/tipos-de-hepatitis-diferencias/

Salud, O. M. (2014). Obtenido de http://www.who.int/features/qa/76/es/

Saludsexualyvidasana.com. (2014). Obtenido de http://saludsexualyvidasana.blogspot.com/2014/09/la-flora-vaginal-bacterias-queconviven.html

Sangro, D. B. (2015). Clinica Universida de Navarra. Obtenido de el diagnóstico se completa con otras determinaciones analíticas que, además, ayudarán a encontrar la causa de la hepatitis y a determinar su severidad y su pronóstico. 